\title{
Hormonal contraception and
} regulation of menstruation: a study of young women's attitudes towards 'having a period'

\author{
Victoria Louise Newton, ${ }^{1}$ Lesley Hoggart ${ }^{2}$
}

${ }^{1}$ Research Associate, Faculty of Health and Social Care, The Open University, Milton Keynes, UK

${ }^{2}$ Senior Lecturer, Faculty of Health and Social Care, The Open University, Milton Keynes, UK

\section{Correspondence to}

Dr Victoria Louise Newton, Faculty of Health and Social Care, The Open University, Horlock Building (H123),

Walton Hall, Milton Keynes MK7 6AA, UK:

victoria.newton@open.ac.uk

- Additional material is published online only. To view please visit the journal online (http://dx.doi.org/10.1136/jprhc2014-100956).

Received 8 April 2014 Revised 29 July 2014 Accepted 13 September 2014 Published Online First 27 October 2014

\section{CrossMark}

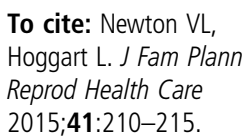

\begin{abstract}
Background Irregular bleeding is one of the most common side effects of hormonal contraception and a key reason for the discontinuation of hormonal methods.

Study design A qualitative study in which 12 young women volunteered to be interviewed in depth, along with six focus group discussions (23 participants). The study had two main research objectives: to document and investigate what young women think and feel about menstruation and contraception, and to explore young women's preferences regarding the intersection of contraceptives and bleeding patterns.
\end{abstract}

Results Although participants held a broad view that menstruation can be an inconvenience, they did ascribe positive values to having a regular bleed. Bleeding was seen as a signifier of nonpregnancy and also an innate part of being a woman. A preference for a 'natural' menstruating body was a strong theme, and the idea of selecting a hormonal contraceptive that might stop the bleeding was not overly popular, unless the young woman suffered with painful natural menstruation. Contraceptives that mimicked the menstrual cycle were acceptable to most, suggesting that cyclic bleeding still holds a symbolic function for women.

Conclusions When counselling young women about the effect of different contraceptive modalities on their bleeding, practitioners should explore how the women feel about their bleeding, including how they might feel if their bleeding stopped or if they experienced erratic bleeding patterns. Practitioners also need to recognise the subjective understanding of the 'natural body' as held by some women, and in these cases to support them in their seeking out of non-hormonal methods of contraception.

\section{INTRODUCTION}

The development of the contraceptive pill gave women greater freedom from
Key message points

- There needs to be an appreciation of the importance of recognising how young women feel about bleeding and its influences on contraceptive choices.

- Subjective understandings of the 'natural body' should be taken seriously when supporting women in their choice of contraception.

- Practitioners need to support women with non-hormonal methods of contraception if this is their preference.

the risk of unintended pregnancy. It also provided women with a method to regulate their monthly bleeding, mimicking a regular menstrual cycle. ${ }^{1}$ More recent developments in hormonal contraception have given women additional options for control over their monthly bleed. ${ }^{2}$ Women can manipulate their combined oral contraceptive regime in order to decrease bleeding episodes, ${ }^{3}{ }^{4}$ or use progestogen-only methods of contraception that may eliminate bleeding altogether.

Embedded in the contrived disruption of bleeding patterns through the use of progestogen-only methods, however, is the possibility that bleeding patterns become altered and/or that unpredictable bleeding patterns become intolerable for women. Widely acknowledged as the most common side effect of hormonal contraceptives, ${ }^{5}$ altered bleeding has been identified by some quantitative studies as the main reason for the discontinuation of hormonal contraception, particularly progestogen-only long-acting methods. ${ }^{6-8}$ 
Existing qualitative studies ${ }^{9} 10$ point to the need for a greater understanding of how and why women's different bleeding patterns may affect their contraceptive choice and adherence.

This study aimed to gain an in-depth understanding into the relationship between young women's views and experiences of menstruation and their attitudes towards hormonal contraception, taking into account the role that cultural and social factors play in contraceptive choices. ${ }^{11} 12$ The basis of the research was a qualitative investigation into the experiences, norms, values and opinions of the young women themselves.

\section{RESEARCH METHODOLOGY}

The methodology proceeded from the understanding that socially and culturally located beliefs and behaviours, with respect to menstrual bleeding preferences, and on contraceptive properties, affect women's contraceptive choices. The study thus had two main research objectives: to document and investigate what young women think and feel about menstruation and contraception; and to explore young women's preferences regarding the intersection of contraceptives and bleeding patterns.

Qualitative data were collected by means of six focus groups (23 participants) and 12 semi-structured one-to-one interviews with young women aged 1621 years (Table 1). Participants were recruited from a CASH (Contraception and Sexual Health) clinic in London, and also through colleges and youth services where the clinic conducts outreach work. When attending an appointment, the young women were introduced to the study by a practitioner or youth worker and were given an information leaflet. If they were interested in taking part they met with the researcher after their appointment, or else provided their contact details for the researcher, if the present time was not convenient for them to take part, or if they wished to take more time to decide whether or not to participate. In total 35 young women volunteered to take part in the study. Over half of the group identified as White British $(n=21)$, the remaining identified as mixed-race $(n=7)$, Black $(n=4)$ or Asian $(n=3)$. The principal researcher obtained written informed consent at the time of the interview/ focus group. The project was approved by a National Health Service research ethics committee.

The topic guides (see online Supplementary Material) were designed to discuss views and experiences of menstruation and bleeding, before moving on to discuss contraceptive choice. Contraception was thereby discussed in relation to feelings about bleeding. The semi-structured questions were phrased in an open-ended manner in order to allow participants to answer fully in their own words. All interviews and focus groups were conducted by the same researcher, except in one instance where two focus groups had taken place in tandem. In this case
Table 1 Qualitative data collection by means of one-to-one interviews and focus groups

\begin{tabular}{|c|c|c|c|}
\hline $\begin{array}{l}\text { Data collection } \\
\text { method }\end{array}$ & $\begin{array}{l}\text { Age } \\
\text { (years) }\end{array}$ & Ethnicity & $\begin{array}{l}\text { Present } \\
\text { contraception }\end{array}$ \\
\hline \multicolumn{4}{|l|}{ Interviews } \\
\hline Jennifer & 21 & $\begin{array}{l}\text { White } \\
\text { British }\end{array}$ & Injection \\
\hline Zoe & 19 & Mixed-race & None \\
\hline Scarlett & 17 & $\begin{array}{l}\text { White } \\
\text { British }\end{array}$ & Implant \\
\hline Lindsay & 19 & $\begin{array}{l}\text { White } \\
\text { British }\end{array}$ & None \\
\hline Anna & 17 & $\begin{array}{l}\text { White } \\
\text { British }\end{array}$ & None \\
\hline Louise & 19 & $\begin{array}{l}\text { White } \\
\text { British }\end{array}$ & Implant \\
\hline Sara & 17 & $\begin{array}{l}\text { White } \\
\text { British }\end{array}$ & Condoms \\
\hline Harriet & 16 & $\begin{array}{l}\text { White } \\
\text { British }\end{array}$ & Patch \\
\hline Audrey & 17 & Mixed-race & None \\
\hline Leah & 18 & Mixed-race & Implant \\
\hline Keisha & 20 & Mixed-race & Condoms \\
\hline Jane & 21 & $\begin{array}{l}\text { White } \\
\text { British }\end{array}$ & Pill \\
\hline \multicolumn{4}{|l|}{ Focus groups } \\
\hline FG01 & $16-21$ & \multicolumn{2}{|c|}{$\begin{array}{l}2 \text { White British, } 1 \text { Asian, } \\
1 \text { Mixed-race }\end{array}$} \\
\hline $\mathrm{FG02}$ & $16-18$ & \multicolumn{2}{|c|}{$\begin{array}{l}2 \text { White British, } 1 \text { Black British, } \\
1 \text { British Asian }\end{array}$} \\
\hline FG03 & $17-19$ & \multicolumn{2}{|c|}{4 White British } \\
\hline FG04 & 17 & \multicolumn{2}{|c|}{2 White British, 1 Mixed-race } \\
\hline FG05 & 16 & \multicolumn{2}{|c|}{3 Black British, 1 Mixed-race } \\
\hline FG06 & $16-17$ & \multicolumn{2}{|c|}{3 White British, 1 Asian } \\
\hline
\end{tabular}

it was necessary for the second researcher to conduct a focus group. Data generated from qualitative research were analysed in order to gain insights into when and why young women might select a contraceptive method that might disrupt their bleeding patterns.

The data were analysed with the help of NVivo software using a form of thematic analysis. ${ }^{13}$ The transcripts were first coded into broad themes. These emerged from the data and concerned the following: Changes in behaviour whilst bleeding; Cleansing; Part of being a woman; Planning and managing; Reassuring; Secrecy and shame; Contraception and reliability; Fertility; Hormones and the body; No periods and regulated periods; Worry about spotting. Each theme was then fine-coded. In this way the analysis was 'grounded' in the data, and the final output based firmly on what the young women themselves had said. Focus group participants are identified as Respondent 1 (R1) and the focus group number (e.g. FG1). Two different methods of qualitative data collection were employed in order to generate data 
that reflect personal accounts of menstruation and contraceptive choice, as well as data concerning more general societal attitudes. Data from the one-to-one interviews provided more nuanced and individualised accounts of bleeding and contraceptive choice, whereas data generated during focus group discussions tended to reflect broader cultural attitudes that were developed through group discussion, rather than through individualised accounts and personal experience narratives. The researcher's coding and interpretation of the data was checked against the original transcripts by a second researcher. Pseudonyms replace the women's actual names for the one-to-one interviews.

\section{RESULTS}

Two major, though related, themes on menstruation were identified: as a natural process it is both unpleasant and necessary; and, for women it is a signifier of the 'normal'. We discuss each of these themes and then we turn to a discussion of how such views may influence contraceptive choices.

The opening questions in the interviews invited participants to express their general feelings towards menstruation. [NB. It is worth noting that participants referred to their bleeding colloquially as 'a period'. We have retained this terminology in the article to reflect their understandings, although we recognise that it lacks physiological accuracy.] Their responses were initially negative, noting that menstruation is messy, painful, inconvenient, and incurs the expense of having to buy tampons and sanitary towels:

\section{R1: "Some don't like the feeling of it bleeding and stuff." \\ R2: "Some don't like the cramps [...] don't like the cramps, don't like..."}

\section{$\mathrm{R} 1:$ "The dirtiness."}

\section{R2: “...the dirtiness, the smell." [FG03]}

This expression of the widespread cultural attitude of menstruation as unpleasant overlay a more nuanced view in which menstruation was conceptualised as a 'natural' part of womanhood, albeit a process which requires intense body management. What was evident from our participants' recollections of managing their bodily bleeding was the impact it had on the way they conducted themselves in their everyday social landscape. This involved planning for their period and being prepared to manage their bodies when their period came. This could be especially difficult in an institutional setting, such as school.

"Well, I take medication for period pain so I have to make sure that I have medication for that otherwise I'll be in agony for, like, two days. And obviously you have to make sure you have your sanitary towels and tampons and stuff like that. And then I always make sure I have one in my bag or one at school in my locker because you have to change it at lunchtime or break time, whatever. Yeah, and you have to like make sure you're not away from the toilet for too long." [FG02, R1]

Participants remarked that they felt insecure about their bodies when they were bleeding. A number recalled wanting to stay at home, or to distance themselves from others. Thus this 'natural' process brought with it insecurities concerning the functioning female body, and these often translated into anxieties clustered around the sensory considerations that needed to be managed, namely visual stains and 'showing', smell and odours:

"I don't really like no one touching me when I'm on my period. I just don't want no one touching me. [...] I mean, yeah, I can have people near me, but I don't want them to touch me, I'm like, 'don't touch me'. [...] I just feel nasty, like in my body.” [Anna]

Bleeding caused a redefinition of the sexual self for some participants, who stated that during their period they would abstain from sexual contact:

"I wouldn't want to have sex when I'm on my period, I actually find that disgusting. Sorry, but that's just a turn-off." [Sara]

The limiting of their social landscape extended to other activities. Swimming was mentioned by a number of participants:

\begin{abstract}
"When I know I'm on my period I just feel like I'm not going swimming neither [...] Even though I could wear Tampax but I still don't [...] Because I'm scared that it'll still come through or something, like even though I got the Tampax on, it might, like... and then someone might spot it and then I'll be like, 'Oh God', and I feel embarrassed by it." [Anna]
\end{abstract}

Menstruation, however, also had positive symbolic meanings for our participants, who discussed valuing their menstruation for two reasons: first, the bleed is a signifier of non-pregnancy; and second, the bleed was viewed as a necessary cleansing process for the body.

The bleed as a signifier of non-pregnancy was a particularly important theme:

"I'd rather not have a period, but then again it's nice if we've got a period isn't it? Cheaper than a pregnancy test, isn't it? You see it and go 'Oh look, I'm not pregnant; everything's alright'.” [Harriet]

For many participants, the view that, as a signifier of the natural body, menstruation is an essential process in the cleansing of the body was important. Participants saw menstrual blood as carrying impurities away from the body. 
"I don't like the thought of never having a period because I believe that, like, your body should be cleared out every month." [Louise]

These complex combinations of - sometimes seemingly contradictory - views on menstruation suggest a perception of the body as both mechanistic and 'natural'. In other words, the body is seen as objective, functioning as it should, with necessary processes taking place (mechanistic), and also as 'natural', through the personal, subjective understandings of the women themselves. These two conceptualisations can be in tension, ${ }^{12}$ as became evident when they were applied to contraceptive choices.

\section{Hormonal contraception and the (un)natural body}

The understanding of menstruation as unpleasant but necessary was a factor in young women's contraceptive choices. The patterns, however, are complex. Participants were using, or had experience of, a number of different hormonal and non-hormonal methods of contraception, and considered a range of different factors in their contraceptive decisionmaking. For some, this included an assessment of the effect the contraception would have on their menstrual cycle. However, this was often secondary to their main reasons for selection: reliability and ease of use. Our analysis focused on understanding relationships between menstruation and ideas about the natural and the normal body, and views on menstrual regulation and contraception.

Many of the young women were concerned about how hormonal contraception might 'mess with' and disrupt the balance of their 'natural' bodies.

"I'm kind of in a view that it's just putting chemicals in my body and I think I've got enough chemicals of my own." [Zoe]

"But you're not sure how the Pill affects your body, like how your body works [...] you don't know what else it can do to all your other organs or whatever, your systems in your body, so I wouldn't take it. I don't know.” [FG02, R4]

Both these comments indicate a reluctance to disrupt their bodies: one referring to 'systems', and the other to 'chemicals'. For some participants the concern about 'chemicals' in the contraceptives extended to the effect these might have on their reproductive capacities in the future:

"There might also be, like, the babies being born with deformities, I don't know if it's like rare, but there might be like a possibility yeah, because of what they've had, maybe the chemicals in the contraception that they've used." [FG01, R4]

Many participants discussed some level of anxiety about the effect of hormonal contraception on the body. However, extreme distrust of hormonal contraception that could lead to a blanket rejection as a method was a marginal concern in our sample. What was more evident was an ambiguity around the relationship between bleeding preferences and the desire to retain a 'natural' body. Using a contraceptive that mimicked the natural cycle so that the body appeared to function as 'normal' was acceptable to most, and could even be considered beneficial. Harriet indicates that using the patch, a method that can be used to mimic the natural cycle, has changed her life for the better by alleviating period pain. She was mainly using this method to help manage her painful natural menstruation:

"I used to go and howl, I used to swear, and I used to shake, I used to be physically sick because of my pain and that and everything. So then I didn't like it and then obviously it interfered with school because the school sends you home or I can't even be in the lesson [...] It's not nice to go through life suffering with your period because it's going to happen once a month ... I never used to go out when I used to come on whereas now I can go out, and it's all better because my pain's better, my period's not... the blood isn't as bad, because it used to be heavy."

A much smaller number of women were prepared to go further than just mimicking their natural cycle. They valued the option of being able to control or limit their periods by using hormonal contraception. They justified biomedical interventions to tame their natural bodies because they felt these bodies were letting them down by subjecting them to extremely painful periods. For example, Jennifer suffered from painful menstruation. She decided to opt for Depo-Provera ${ }^{\circledR}$, which can induce amenorrhoea, and appreciated no longer having to worry about managing her menstruation:

"I remember them being quite painful, that's why I sort of decided to go on the injection because I didn't really want that pain every month."

Another group of participants prioritised reproductive control over any effect the contraception would have on their bleeding patterns, and were happy to surrender their bodies to biomedical interventions and tolerate side effects in exchange for having ultimate reproductive control.

Whereas controlling bleeding through contraceptive use was acceptable to some young women, what was completely unacceptable (to almost all) was the possibility of experiencing irregular bleeding as a side effect of contraception.

Irregular bleeding as a side effect - body 'out of control' Progestogen-only methods (progestogen-only pills, Depo-Provera, implant, intrauterine system) can be associated with disrupted bleeding patterns. Managing the breakthrough bleeding, or spotting between periods, was subject to the same issues as menstruation as regards body management, but the changed and unpredictable nature of it made it more problematic for the young women. Participants also voiced anxiety about where 
such additional blood was coming from that reflected concerns about a malfunctioning or damaged body:

"Because when you normally have a period it lasts five days at most - well, mine normally last five days at most. I'm thinking 'Well, where is all this other blood coming from?' It was making me panic: 'Is there something wrong with me and have they damaged me by putting it in?' So I get a bit panicky about things like that." [Keisha]

\section{DISCUSSION}

The choice to use hormonal contraception, taking into account its impact on bleeding patterns, is highly subjective and differs between individual women. It is influenced, among other factors, by women's understanding of, and their relationship to, their reproductive bodies, where a division exists between groups of women who like to experience a regular bleed and others who prefer a less frequent bleed. Our analysis of the relationship between participant understandings about menstruation and contraception has shown that views on menstruation could influence contraceptive choice and adherence in subtle ways.

The sample size for the project was limited through constraints of funding. This limitation means that it is not possible to generalise our findings to the wider population. However, in common with another recent study, ${ }^{12}$ we noted an aversion to the idea of disrupting the 'natural' body. Such interference could be tolerated when there was great concern and anxiety about pregnancy avoidance; and/or when the young women's experiences of menstruation were extremely unpleasant. In both these circumstances, biomedical intervention that led to controlled bleeding or no bleeding was acceptable or even desirable.

Another situation in which controlled bleeding was acceptable represented a compromise: many participants were prepared to consider acceptance of hormonal contraception that mimics the menstrual cycle, and this may indicate ambivalence or inconsistency with respect to feelings about a 'natural' body. One important reason for this preference was the importance attached to the visibility of a bleed as a signal of non-pregnancy, and this has been noted in other studies. ${ }^{14} 15$ Our study would, however, indicate deeper additional reasons for this preference, and these echo the findings of an international study in that "the process of menstruation carries deep cultural and personal significance for women. This significance persists even in the face of a modern understanding of menstruation, and the ability to manipulate menses with medication". ${ }^{2}$

Although the bleeding that women experience with combined oral contraceptives during their pill-free 7-day break is a withdrawal bleed and not a natural biological menstruation, participants in the study understood any type of bleeding in terms of 'their period'. They did not differentiate between menstruation, a withdrawal bleed, or breakthrough bleeding. The vernacular term 'period' allowed them to name their bleeding in a way that was both straightforward and understood, and also loaded with the common cultural conventions that shape their experiences. ${ }^{16}$

Echoing other studies, prolonged and irregular bleeding was viewed as unacceptable. ${ }^{14}{ }^{17-20}$ Because having a period is a culturally loaded process for women, they manage their bodies so as to present no outwardly physical sign that they are bleeding. This process of body management involves body watching and planning. The young women in our study viewed any 'breakthrough bleeding' as an experience they likened to menstruation with the added concern of unpredictability, thus heightening concerns about body watching.

The study participants, on the whole, did not consider that the possibility of changed bleeding patterns was a significant driver in their choice of contraception unless they suffered from painful or heavy menstruation. A minority were receptive to the idea of utilising hormonal contraception in order to avoid bleeding altogether, but this was not the main reason for selecting an amenorrhoeic method, rather it was an added benefit. This suggests that the possibility of amenorrhoea may not be an especially strong 'selling point' of progestogen-only methods. The reliability and ease of use of any chosen means of contraception was a much more important consideration. An indifference to amenorrhoeic methods was possibly linked to anxieties around not-bleeding as a signifier of an underlying pregnancy. It could additionally be informed by cultural understandings of the bleed as being a necessary process in the cleansing of the female body.

The theme of menstruation as a natural cleansing was strong in the data, despite the fact that having regular menstrual periods is not what 'nature' intended. If 'left to nature', most women would have relatively few menstrual periods during their reproductive years, since they would be repeatedly pregnant or breastfeeding. Because most women take measures to avoid repeated pregnancies, monthly menstruation has become a 'side effect' of modern reproductive life. However, menstruation was seen by participants in our study as an important signifier that the body was functioning 'as it should'. Although it should be born in mind that the age of these participants militated against them contemplating the unnaturalness of decades of pregnancy avoidance per se, the misapprehension about what may or may not be natural could have implications for better education about menstrual periods, body awareness, sex, and the physiology involved.

With many bleeding options and side effects to consider, contraceptive decision-making is a complex process and subject to many influencing factors. In results similar to those of Cheung and Free $^{10}$ we found that in the case of hormonal contraception, decision-making is influenced by the meaning of unwanted side effects within the framework of 
established and underlying beliefs regarding hormones, the body and 'natural' menstruation, as well as to bodily control of the menstrual cycle and the avoidance of pregnancy. Also included here is the rejection of hormonal contraception because of its interference with the natural menstrual cycle.

Furthermore, our study shows women to be seeking out individualised versions of 'control' in accordance with their own personal priorities: control of their fertile bodies, control of the menses, or control to guard against unwanted side effects.

\section{CONCLUSIONS}

The results of our study suggest that there is a relationship between young women's views on menstruation and their contraceptive preferences. Those women who were very committed to the 'natural' were distrustful of hormonal contraception. Those with more of an ambiguous view on the 'natural', such that mimicking the natural cycle was acceptable, would select a hormonal contraception that did just this. The young women were prepared to consider methods that might disrupt bleeding only if they suffered very badly when menstruating, or prioritised pregnancy avoidance over bleeding anxieties. And even in these cases, there was an underlying anxiety created by removing the 'period' as signifier of non-pregnancy. The study adds to other qualitative studies already mentioned in making a case for integrating discussions of bleeding preferences in contraceptive consultations. When counselling young women about the effect of hormonal contraception on their bleeding, practitioners should explore how the young women feel about their bleeding, and how they might feel about unpredictable bleeding, as well as outlining the therapeutic interventions available to alleviate breakthrough bleeding. ${ }^{21}$ In some cases they might need to help women with nonhormonal methods of contraception, including male and female barrier methods and fertility awareness methods, whilst at the same time making the women aware that, in general use, these methods are less reliable. Moreover, some women will be concerned about the effect of hormonal contraception on what is perceived as the natural working of their body, and these subjective understandings of 'natural body' should be taken seriously when supporting women in their choice of contraception.

Funding British Academy Small Grant (SG111265).

Competing interests None.

Ethics approval NHS REC London - Brent.

Provenance and peer review Not commissioned; externally peer reviewed.

\section{REFERENCES}

1 Read CM. New regimens with combined oral contraceptive pills - moving away from the traditional 21/7 cycles. Eur J Contracept Reprod Health Care 2010;15(S2):S32-S41.
2 d'Arcangues C, Jackson E, Brache V, et al. Women's views and experiences of their vaginal bleeding patterns: an international perspective from Norplant users. Eur J Contracept Reprod Health Care 2011;16:9-17.

3 Repta R, Clarke LH. 'Am I going to be natural or am I not?': Canadian women's perceptions and experiences of menstrual supression. Sex Roles 2013;68:91-106.

4 Lakehomer H, Kaplan PF, Wozniak DG, et al. Characteristics of scheduled bleeding manipulation with combined hormonal contraception in university students. Contraception 2013;88:426-430.

5 French K. Sexual Health. Oxford, UK: Wiley-Blackwell, 2009.

6 Harel Z, Biro FM, Kollar LM, et al. Adolescents' reasons for and experience after discontinuation of the long-acting contraceptives Depo-Provera and Norplant. J Adolesc Health 1996;19:118-123.

7 Rai K, Gupta S, Cotter S. Experience with Implanon ${ }^{\circledR}$ in a north-east London family planning clinic. Eur J Contracept Reprod Health Care 2004;9:39-46.

8 Lakha F, Glasier AF. Continuation rates of Implanon ${ }^{\circledR}$ in the UK: data from an observational study in a clinical setting. Contraception 2006;74:287-289.

9 Hoggart L, Newton VL, Dickson J. Understanding LARC Adherence: An In-depth Investigation into Sub-dermal Contraceptive Implant Removal Amongst Teenagers in London. London, UK: London Sexual Health Commissioning Programme, 2013.

10 Cheung E, Free C. Factors influencing young women's decision making regarding hormonal contraceptives: a qualitative study. Contraception 2005;71:426-431.

11 Trussell J. Understanding contraceptive failure. Best Pract Res Clin Obstet Gynaecol 2009;23:199-209.

12 Walker S. Mechanistic and 'natural' body metaphors and their effects on attitudes to hormonal contraception. Women Health 2012;52:788-803.

13 Braun V, Clarke V. Using thematic analysis in psychology. Qual Res Psychol 2006;3:77-101.

14 Edwards JE, Oldman A, Smith L, et al. Women's knowledge of, and attitudes to, contraceptive effectiveness and adverse health effects. Br J Fam Plann 2000;26:73-80.

15 Williamson LM, Buston K, Sweeting H. Young women's continued use of oral contraceptives over other hormonal methods: findings from a qualitative study. J Fam Plann Reprod Health Care 2009;35:167-172.

16 Newton VL. Status passage, stigma and menstrual management: 'Starting' and 'Being On'. Soc Theory Health 2012;10:392-407.

17 Clark LR. Will the pill make me sterile? Addressing reproductive health concerns and strategies to improve adherence to hormonal contraceptive regimens in adolescent girls. J Pediatr Adolesc Gynecol 2001;14:153-162.

18 Clark LR, Barnes-Harper KT, Ginsburg KR, et al. Menstrual irregularity from hormonal contraception: a cause of reproductive health concerns in minority adolescent young women. Contraception 2006;74:214-219.

19 Wong RC, Bell RJ, Thunuguntla K, et al. Implanon users are less likely to be satisfied with their contraception after 6 months than IUD users. Contraception 2009;80:452-456.

20 Jeffreys AL, Clark AL. A successful approach to long-acting contraceptive implants in primary care. Contraception 2012;85:381-383.

21 Dickson J, Hoggart L, Newton VL. Unanticipated bleeding with the etonogestrel implant: advice and therapeutic interventions. J Fam Plann Reprod Health Care 2014; 40:158-160. 